\title{
Echocardiographic diagnosis and necropsy findings of a congenital ventricular septal defect in a stranded harbor porpoise
}

\author{
Viktor Szatmári ${ }^{1, *}$, Paulien Bunskoek ${ }^{2,3}$, Thijs Kuiken ${ }^{4}$, Annemarie van den Berg ${ }^{3}$, \\ Cornelis van $\mathrm{Elk}^{2,3,4}$ \\ ${ }^{1}$ Department of Clinical Sciences of Companion Animals, Faculty of Veterinary Medicine, Utrecht University, Yalelaan 108, \\ 3584 CM, Utrecht, the Netherlands \\ ${ }^{2}$ Dolfinarium, Strandboulevard Oost 1, $3841 \mathrm{AB}$, Harderwijk, the Netherlands \\ ${ }^{3}$ SOS Dolfijn, Strekdam 49, 3841 WD, Harderwijk, the Netherlands \\ ${ }^{4}$ Department of Viroscience, Erasmus Medical Centre, Wytemaweg 80, Ee 1726, 3015 CN, Rotterdam, the Netherlands
}

\begin{abstract}
A live-stranded harbor porpoise Phocoena phocoena was found on the west coast of the Dutch island Texel (North Sea) and transported to a rehabilitation center for small cetaceans, where it underwent a veterinary health check. Cardiac auscultation revealed a systolic cardiac murmur with the point of maximal intensity in the right hemithorax with an intensity of IV out of VI. Transthoracic echocardiography revealed a congenital ventricular septal defect with left-toright shunting. Because the left atrium was not dilated according to the reference range of canine left atrium to aortic ratio, the presence of congestive heart failure was considered very unlikely. Therefore, this congenital cardiac anomaly was thought to be a clinically non-relevant incidental finding and would not explain the weakness, coughing, anorexia, vomiting, and diarrhea. Because the animal was still unable to swim or eat by itself after 2 wk of supportive care, it was euthanized. Post-mortem examination confirmed the presence of a ventricular septal defect. The weight of the heart relative to the animal's length was greater than expected, using linear regression analysis on the lengths and cardiac weights of 71 other stranded wild harbor porpoises without macroscopic cardiac pathologic changes. This finding suggests that the left ventricle had an eccentric hypertrophy because of volume overload resulting from the intracardiac shunt. This is the first report of a congenital cardiac anomaly and its ante-mortem diagnosis in this species. Data presented for the other 71 harbor porpoises may provide reference values for this species.
\end{abstract}

KEY WORDS: Heart · Phocoena phocoena $\cdot$ Cetacean · Aquatic mammal · Cardiac shunt

\section{ANTE-MORTEM FINDINGS}

In January 2015, a live-stranded harbor porpoise Phocoena phocoena was found on the western coast of Texel, a Dutch island located in the North Sea. The animal was a female weighing $23.4 \mathrm{~kg}$ with a length of $112 \mathrm{~cm}$ and an estimated age of 7 mo, based on its stranding date, body weight, and length. Within several hours, it was transported to
SOS Dolfijn, a rehabilitation center for stranded wild small cetaceans in the Netherlands.

Physical examination carried out by a veterinarian upon arrival revealed abdominal discomfort and frequent flatulence. Small wounds were noticed on the rostrum, the leading edge of the left fluke, the trailing edge of the right fluke, the leading edge of the dorsal fin, the leading edge of the left pectoral flipper, and on the lower and upper jaws. On auscultation, an av- 
erage heart rate of 80 beats per minute (bpm), a IV out of VI systolic cardiac murmur with the point of maximal intensity on the right hemithorax, and respiratory arrhythmia were found. The average heart rate of $80 \mathrm{bpm}$ was interpreted as normal for this species (Reed et al. 2000). The heart rate immediately following a respiratory excursion was $140 \mathrm{bpm}$, and just prior to the next exhalation-inhalation it slowed to $60 \mathrm{bpm}$. This respiratory arrhythmia is a physiologic finding in this species (Kastelein \& Meijler 1989).

Blood tests showed mild anemia (hematocrit 0.421 $\mathrm{l}^{-1}$; reference $\left.0.45-0.521 \mathrm{l}^{-1}\right)$, mild leukocytosis $(8.6 \times$ $10^{9} \mathrm{l}^{-1}$; reference $2-5 \times 10^{9} \mathrm{l}^{-1}$ ), mildly elevated fibrinogen concentration $\left(1.9 \mathrm{~g} \mathrm{l}^{-1}\right.$; reference $\left.<1.8 \mathrm{~g} \mathrm{l}^{-1}\right)$, and elevated lactate dehydrogenase $\left(792 \mathrm{IU} \mathrm{l}^{-1}\right.$; reference $<450 \mathrm{IU} \mathrm{l}^{-1}$ ). Bronchoscopy was performed in the awake, non-sedated animal via the blowhole. This examination did not show any abnormalities. Fecal cytology showed a large number of leukocytes (too numerous to count at $400 \times$ magnification). Abdominal ultrasonography was performed. The only abnormality seen in the abdomen was a large amount of intestinal gas. Based on the abdominal discomfort, fecal cytology, and ultrasonographic findings, enteritis was suspected.

The animal needed continuous nursing care, as it was unable to swim or eat by itself. In the rehabilitation center, the animal coughed 8 to 31 times d $^{-1}$. The feces were persistently abnormal (i.e. green and watery), and had a variable consistency (intermittently floated, variably contained mucus, and occasionally were firm and sank). The respiratory rate varied from 10 to 15 breaths per $5 \mathrm{~min}$, and the average heart rate varied from 72 to $84 \mathrm{bpm}$, both of which were considered to be normal for the species. Treatment was initiated with enrofloxacin $\left(5 \mathrm{mg} \mathrm{kg}^{-1}\right.$ oral tablets twice daily) as an antibiotic, simethicone (62.5 $\mathrm{mg}$ oral powder twice daily) to reduce the amount of intestinal gas accumulation, and tramadol ( $0.5 \mathrm{mg} \mathrm{kg}{ }^{-1}$ oral suspension twice daily) as analgesia. Enrofloxacin was chosen because of positive experience with this antibiotic drug in this species with intestinal problems in our rehabilitation center. The animal was rehydrated with $200 \mathrm{ml}$ of $0.45 \%$ $\mathrm{NaCl}$ solution via an orogastric tube every $2 \mathrm{~h}$ for the first $12 \mathrm{~h}$. Subsequently, forced feeding was initiated with $800 \mathrm{~g}$ of fish (herring and sprat) divided into 8 daily portions and $600 \mathrm{ml}$ of $1.35 \% \mathrm{NaCl}$ solution divided into 3 daily portions. Two days after admittance to the rehabilitation center, the animal vomited a large amount of fluid with some partly digested pieces of fish. It also began resisting forced feeding of whole fish but still allowed the orogastric tube to pass. Because in the past harbor porpoises have shown adverse reactions to the anti-emetic metoclopramide and there is no experience with other antiemetics in this species, we decided to cease feeding with whole fish and initiated feeding the animal with 'fish formula' (1 kg of deboned herring mixed with $1 \mathrm{l}$ of $0.9 \% \mathrm{NaCl}$ solution) instead. The hope with this dietary change was that the animal would stop vomiting. During the rehabilitation period, 800 to $1400 \mathrm{ml}$ of this formula were given per day $(950-1750 \mathrm{kcal}$ $\left.\mathrm{d}^{-1}\right)$, divided into 12 portions. After this change in the feeding regime, the animal vomited a small amount of fluid on Days 3 and 5 of the rehabilitation period, and thereafter no more vomiting was noticed. After $3 \mathrm{~d}$, the simethicone dose was increased to $62.5 \mathrm{mg}$ 3 times $\mathrm{d}^{-1}$. As the intestinal problems did not seem to resolve with treatment, after $8 \mathrm{~d}$, the enrofloxacin was switched to metronidazole $\left(7 \mathrm{mg} \mathrm{kg}^{-1}\right.$ oral tablet twice daily), and the tramadol dosage was decreased to $0.25 \mathrm{mg} \mathrm{kg}^{-1}$ twice daily. Metronidazole was chosen not only because of its well known anaerobic antimicrobial activity and safety in this species, but also because of its anti-inflammatory effect (Shakir et al. 2011). The change of antibiotic was decided because clinical improvement would be expected within $1 \mathrm{wk}$ in the case of effective antimicrobial therapy.

During the $11 \mathrm{~d}$ rehabilitation period, the animal did not show any clinical improvement, did not eat on its own, and was unable to swim. Repeated fecal sampling continued to demonstrate a large number of leukocytes on cytology. Because of the lack of clinical improvement during the rehabilitation period despite the intensive nursing and the presumably poor long-term prognosis because of the congenital cardiac anomaly, no further diagnostic investigations were performed on the gastrointestinal tract. Therefore we are unable to provide an explanation for the origin and the continued presence of leukocytes in the feces. The choice and timing of the applied antimicrobial therapy was empiric, based on experience of experts in this field, as there are no studies available that would support the use of a specific antibiotic in this species for suspected enteritis.

Eleven days after stranding, an echocardiographic examination was performed with the animal in ventral recumbency on an examination table by a boardcertified veterinary cardiologist (V.S.; Fig. 1). A 3.5 $\mathrm{MHz}$ phased array transducer was used (Esaote, MyLab30VetGold), and the heart was scanned from the right and left parasternal transthoracic views according to standard views used in dogs (Thomas et al. 1993). Compared to dogs, the acoustic window 
was remarkably large, which made transthoracic echocardiography surprisingly easy to perform. This may indicate that the lungs do not wrap as much around the heart as they do in Tursiops (Sklansky et al. 2006). A ventricular septal defect (VSD) was found located just proximal to the aortic valve with a diameter of approximately $8 \mathrm{~mm}$ (Fig. 2). The aortic diameter at the level of the valve was $24.5 \mathrm{~mm}$. Color Doppler examination revealed left-to-right shunting of blood through the VSD. Continuous wave Doppler examination revealed a peak velocity of $4.96 \mathrm{~m} \mathrm{~s}^{-1}$ of the shunting blood, which is compatible with a pressure gradient of $98 \mathrm{mmHg}$ between the left and right ventricles according to the modified Bernoulli equation (pressure gradient $=4 v^{2}$, where $v=$ blood flow velocity). The opening of the VSD into the right ventricle was adjacent to the tricuspid valve. In addition to the VSD, mild aortic and moderate pulmonic valve regurgitation and 2 small tricuspid regurgitant jets were noted on color Doppler images. The peak velocity of the pulmonic valve regurgitant jet was $3.1 \mathrm{~m} \mathrm{~s}^{-1}$,

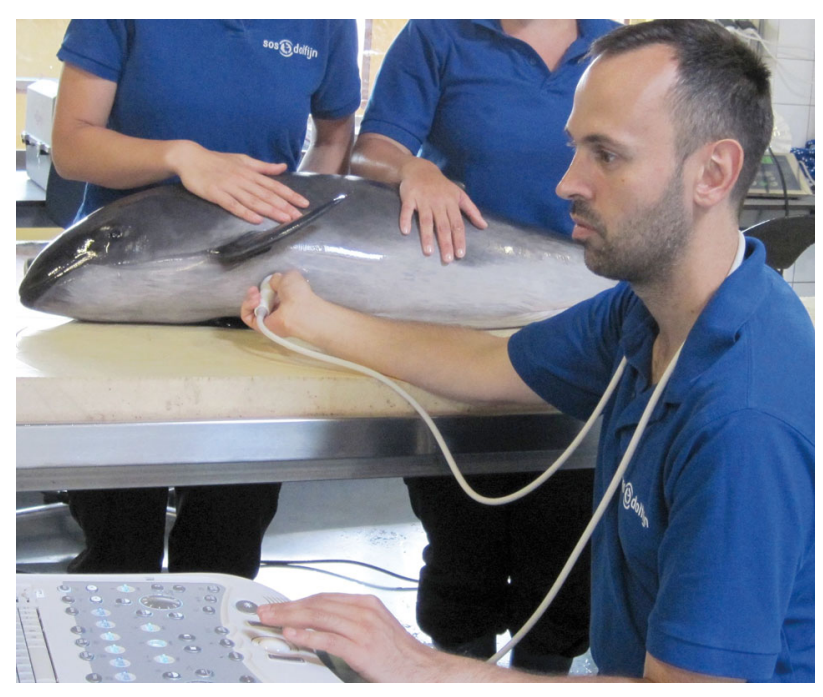

Fig. 1. Echocardiographic examination of the harbor porpoise Phocoena phocoena on a solid examination table. The animal was gently restrained and tilted by 2 assistants, who also kept the animal constantly wet using a sponge soaked with sea water

Fig. 2. (a,b) Standard right parasternal long axis transthoracic views of the harbor porpoise Phocoena phocoena. (a) 2-dimensional short-axis echocardiographic image of the aorta (AO), ventricular septal defect (VSD, ${ }^{*}$ ), and left atrium (LA). The LA:AO ratio is 1.5. RA: right atrium; RV: right ventricle; PA: main pulmonary artery. (b) Color Doppler echocardiographic image showing high velocity blood flow (light blue) through the VSD from the left ventricle (LV) to the RV. Arrows indicate the direction of blood flow. IVS: interventricular septum; LVW: left ventricular free wall. (c) M-mode echocardiographic image of the LV from the transthoracic right parasternal short axis view. The periodically changing slow and quick heart rate is the result of respiratory arrhythmia, which is physiologic in harbor porpoises. Note that the RV has a similarly large lumen and wall thickness to that of the LV (on the 2-dimensional image), which is normal in this species (V. Szatmári pers. obs.), in contrast to terrestrial mammals 
which, after applying the modified Bernoulli formula, indicated a mean pulmonary arterial pressure of $38 \mathrm{mmHg}$. This value would be consistent with mild pulmonary hypertension in dogs (Johnson 1999). The blood flow velocity of the tricuspid regurgitant jets were not measured because the pulmonic valve regurgitation jet was larger, thus easier to measure, and because the presence of 2 regurgitant jets of the tricuspid valve would have given an unreliable Doppler-derived pressure gradient value. Moreover, the duration of the echocardiographic examination was restricted so as to minimize the stress to the animal being out of water. The left atrial to aortic ratio was 1.5, measured on 2-dimensional images according to the Swedish method (Hansson et al. 2002). This was interpreted as high normal based on canine reference ranges (i.e. no left atrial dilatation was present). Left atrial enlargement would be present from a ratio of 1.6 and higher (Rishniw \& Erb 2000b). No mitral valve regurgitation was apparent on color Doppler images. Based on the echocardiographic findings, a congenital left-to-right shunting restrictive VSD was diagnosed (Kittleson 1998, Boon 2011, Penny \& Vick 2011). As no clinical improvement was noted within $2 \mathrm{wk}$ of stranding, the animal was euthanized.

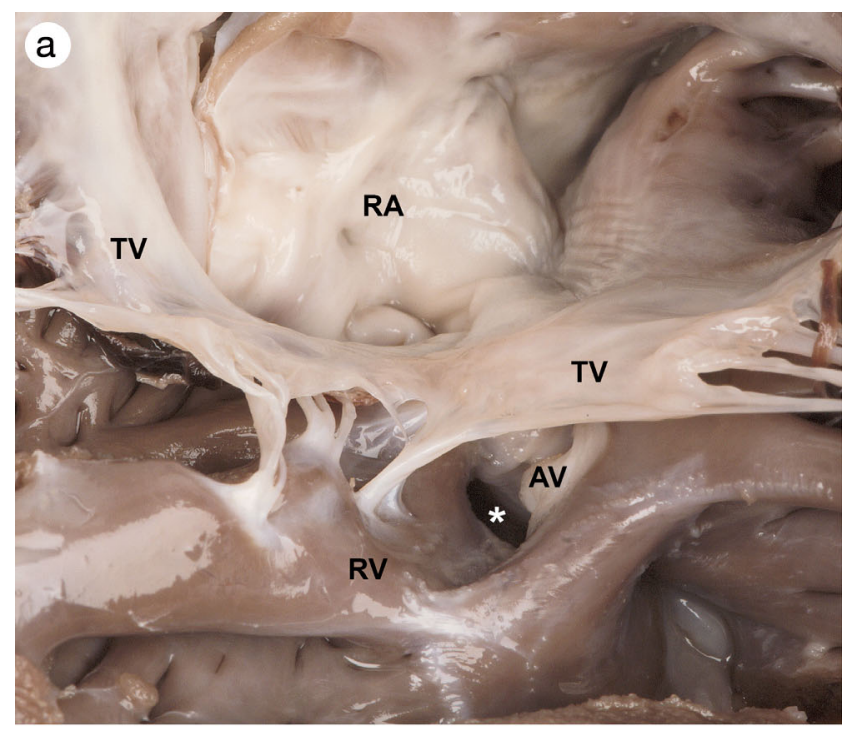

Fig. 3. Formaldehyde-fixed heart of the harbor porpoise Phocoena phocoena. (a) View from the right ventricle (RV). The RV and right atrium (RA) are opened. A ventricular septal defect (VSD, ${ }^{*}$ ) can be seen as a hole directly underneath the tricuspid valve (TV). The aortic valves (AV) can be seen through and adjacent to the defect. (b) View from the left ventricle (LV). Here, the VSD $\left({ }^{*}\right)$ is directly underneath the AV (right leaflet). AO: aorta; MV: mitral valve; PM: papillary muscle

\section{POST-MORTEM FINDINGS}

Post-mortem examination confirmed the presence of the VSD. The defect was seen as a round hole of $10 \mathrm{~mm}$ in diameter, located at the dorsal edge of the interventricular septum (Fig. 3). From the side of the right ventricle, the defect opened into the right ventricular inlet and was located between the supraventricular crest and the edge of the right atrioventricular valve. From the side of the left ventricle, it was located immediately below the right semilunar cusp of the aortic valve. According to the classification of Penny \& Vick (2011), this VSD was a muscular one. The weight of the heart was $250 \mathrm{~g}$. Gross examination of the other organs did not reveal any further relevant changes in this animal. In order to interpret the cardiac weight, reference values had to be established. The heart weights of 71 harbor porpoises were found in the archives of the Department of Viroscience of the Erasmus Medical Centre in Rotterdam, the Netherlands. Linear regression analysis of the heart weights and body lengths was carried out using a commercial statistical program (SPSS 21.0, IBM Statistics). This analysis resulted in the following mathematical relationship between the body length $(x)$ and weight of the heart $(y): y=3.4249 x-222.14$

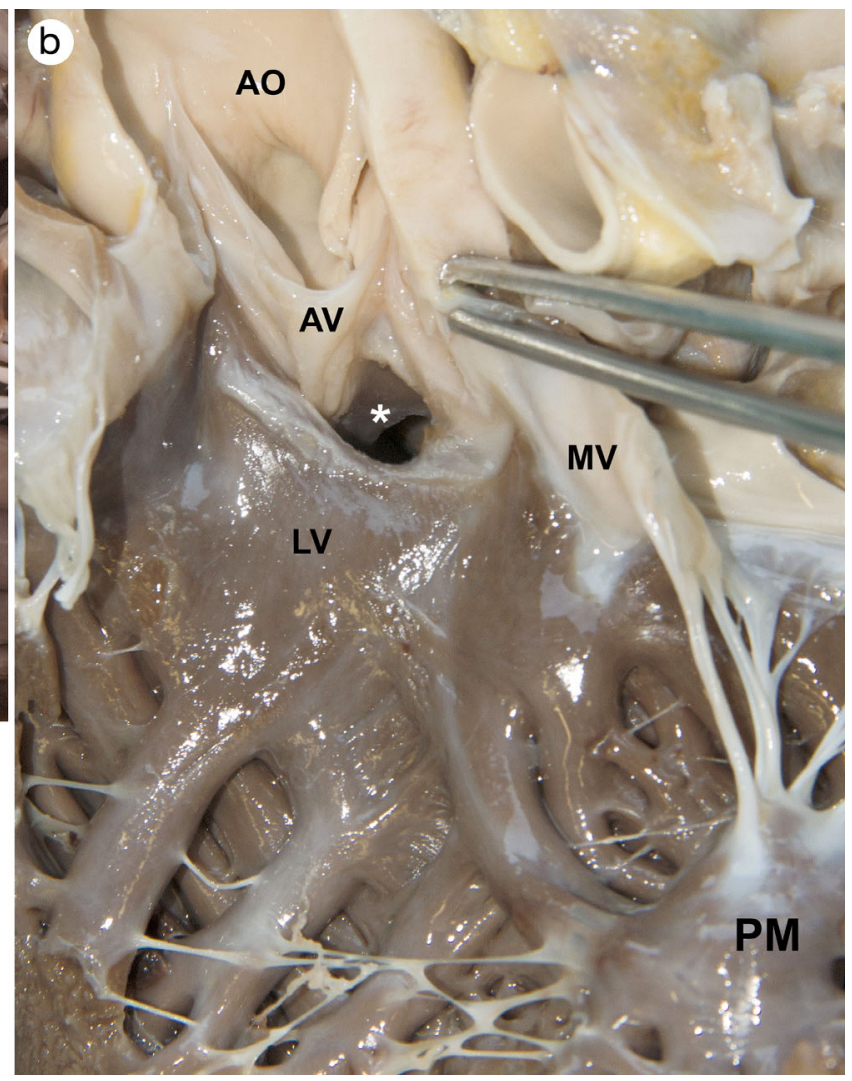


$\left(R^{2}=0.7905 ;\right.$ standard error on slope $\left.=0.209\right)$. The cardiac weight of the studied animal was higher than the expected calculated weight based on its length $(p<0.05)$ (Fig. 4, Table S1 in the Supplement at www.int-res.com/articles/suppl/d118p177_supp.pdf).

\section{DISCUSSION}

To our knowledge, this is the first report of a congenital cardiac anomaly in a harbor porpoise (Gray \& Conklin 1974, Powell et al. 2009, Scaglione et al. 2013). In addition, we are not aware of any previous reports of a congenital cardiac anomaly diagnosed with transthoracic echocardiography in a live harbor porpoise. The relatively small size of this species makes it possible to place the animal on an examination table, such that an echocardiographic examination does not necessarily need to take place with the animal immersed in water. The examination table was solid without a cut-out, covered with a mattress. The animal was scanned by slightly tilting it to one side. The other advantage of the size of the harbor porpoise is that transthoracic echocardiography is a feasible technique. The large size of bottlenose dolphins requires the use of transesophageal or in-water transthoracic echocardiography. Numerous disadvantages of these techniques include limited availability of a transesophageal transducer because of its

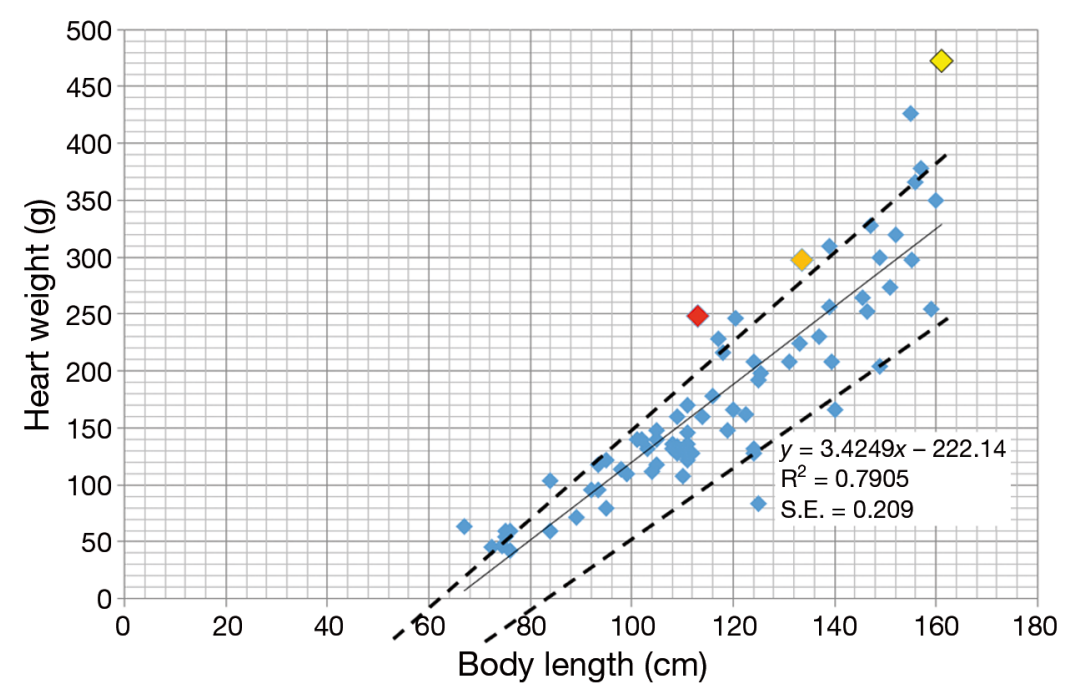

Fig. 4. Heart weights of 71 harbor porpoises Phocoena phocoena that died during rehabilitation without cardiac changes on gross pathology. Dashed lines are $95 \%$ confidence intervals. The red dot indicates the animal with the ventricular septal defect described in this case report, whose heart weight is higher than expected for its size $(\mathrm{p}<0.05)$, indicating hypertrophy. The orange and yellow dots are porpoises with myocarditis and pericarditis, respectively high costs, requiring a trained animal for accepting the insertion of a transesophageal transducer, difficulty in protecting the scanner from water damage, and challenging (i.e. unstable and uncomfortable) body position of the investigator requiring either standing in the water on the slippery base of the basin or in a squat or kneeling position leaning from the edge of the basin over the animal that is completely immersed and manually restrained in the water (Sklansky et al. 2006, authors' unpubl. obs.).

The VSD in this animal was thought to be an incidental finding. The amount of shunting flow depends on the size of the defect and the relative resistances of the systemic and pulmonary vasculature (Penny \& Vick 2011). The smaller, so-called restrictive, VSDs provide resistance to pressure. Although no uniformly accepted criteria exist to define a restrictive VSD, the following parameters have been proposed: cross-sectional area of the VSD compared to that of the aortic orifice, blood flow velocity across the VSD, and diameter of the VSD relative to the body surface area (Penny \& Vick 2011). The velocity of shunting blood in a restrictive VSD would be expected to vary between 4.6 and $5.8 \mathrm{~m} \mathrm{~s}^{-1}$ (Kittleson 1998). Moderatesized VSDs offer resistance to pressure but hardly any resistance to flow, and the surface area of the defect is smaller than the aortic valve region (Kittleson 1998). Over time, a left-to-right shunting VSD leads to volume overload of the left ventricle if the shunting volume is large enough (i.e. moderate and large defects). As a result of increased wall stress, eccentric hypertrophy of the left ventricle develops. Small VSDs do not result in left-sided cardiomegaly (Kittleson 1998, Boon 2011). In individuals with relatively large defects without pulmonary vascular disease, rise in volume loading of the left atrium and ventricle results in left heart dilation (Penny \& Vick 2011). This may eventually result in cardiogenic pulmonary edema (i.e. congestive left-sided heart failure). Before this stage is reached, the left atrium becomes enlarged. The left atrium was thought to be of normal size in our harbor porpoise based on the canine reference cut-off value of the left atrial to aortic ratio. This ratio is a dimensionless value and is independent of body weight (Rishniw \& Erb 2000b, Hansson et al. 2002). Moreover, no tachypnea or dyspnea were present, which are characteristic findings of pul- 
monary edema in other species. If we extrapolate the findings from dogs with a small or medium-sized VSD to this harbor porpoise, no clinical signs such as exercise intolerance would be expected. As echocardiographic reference values are lacking for the left ventricular lumen and wall dimensions in the harbor porpoise, it is difficult to say whether the left ventricle had developed eccentric hypertrophy as a result of volume overload. Subjective assessment of the size of the left ventricular lumen in diastole compared to the left ventricular wall thickness and to the right ventricular lumen may be indicative of volume overload in individuals with a large amount of shunting. Bulging of the interventricular septum towards the right ventricle may indicate mild to moderate volume overload. Severe volume overload of the left ventricle would result in a rounded left ventricular apex, which can be quantified with the so called sphericity index (Ljungvall et al. 2011). In this animal, the left ventricular lumen in diastole seemed to be subjectively normal in size and shape, but objective assessment is not possible without species-specific reference values (Cornell et al. 2004, Boon 2011). These data would be needed to decide whether the VSD would clinically be classified as small or moderate in size (Kittleson 1998, Boon 2011). However, because the heart weight of this animal at necropsy was higher than expected for this given length of harbor porpoise, cardiac hypertrophy was confirmed and thus volume overload was suspected. This finding leads to a classification of the VSD as moderate in size. Histopathologic examination was performed of all organs. No microscopic abnormalities were detected on the myocardium samples taken from the left and right ventricles. Leftto-right shunting VSD may lead to pulmonary hypertension, which does not necessarily cause clinical signs, especially if it is mild or moderate (Johnson 1999, Penny \& Vick 2011). Aortic regurgitation is a common finding in dogs and humans with VSD because of the subvalvular location of the defect, which leads to aortic valve insufficiency (Kittleson 1998, Boon 2011). The near location of the ventricular septal defect and the aortic valve results in an absence of structural support of the aortic valve and in turn prolapse of an aortic valve leaflet into the defect (Penny \& Vick 2011). As pulmonic and tricuspid valve regurgitation is known to be physiologic in dogs, cats, and humans, this may also be the case in other mammals such as the harbor porpoise (Rishniw \& Erb 2000a).

The cause of coughing in this animal could not be determined with clinical, bronchoscopic, or even with gross pathologic and histopathologic examina- tions. Cardiogenic pulmonary edema was thought to be a very unlikely clinical diagnosis because of the normal bronchoscopic findings and the lack of left atrial enlargement on echocardiography. Further investigations, such as thoracic radiographs and bronchoalveolar lavage, might have revealed the cause, but because coughing was not the major clinical problem in this animal, these tests were not performed.

Post-mortem examination could not detect any abnormalities in the gastrointestinal tract. Thus no explanation can be given for the clinically observed problems of vomiting, anorexia, and diarrhea.

How underwater immersion might have influenced the clinical signs and cardiac changes in this animal is difficult to say. Information known about diving human beings may cautiously be extrapolated to this case. Once an individual is immersed in water, a central shift of a large amount of blood can be expected because of increased external pressure on the venous system (Bove 2011). This may increase the left ventricular volume overload in an individual with a moderate sized VSD, leading to acute cardiogenic pulmonary edema or worsening the severity of pulmonary hypertension. Both scenarios could lead to dyspnea and exercise intolerance. Reversal of the shunt direction during immersion is very unlikely, as right-to-left shunting (Eisenmenger's syndrome) would have caused erythrocytosis (Kittleson 1998). However, hematocrit values were not increased, but rather mildly decreased, in this animal.

The prevalence of congenital cardiac anomalies in cetaceans is unknown. From 1982 to 2015 (33 yr), 156 stranded wild harbor porpoises have been examined by 1 veterinarian at the SOS Dolfijn foundation in Harderwijk. In that time period, a cardiac murmur was found in only 1 animal, viz. the one described herein (which equates to a prevalence of $0.6 \%$ ). Whether this prevalence reflects that of the wild population is unknown, and whether VSD represents the most common congenital cardiac anomaly in this species is also unknown.

In conclusion, this is the first report of an antemortem diagnosis and pathologic description of a congenital VSD in a stranded wild harbor porpoise. We also report the heart weights of a large number of harbor porpoises to serve as reference values for this species.

Acknowledgements. We thank David van de Vijver for his help in the statistical analysis. We also thank the staff and volunteers of SOS Dolfijn for taking care of this particular porpoise and all other stranded animals and assisting in all of the veterinary procedures. 


\section{LITERATURE CITED}

Boon JA (2011) Veterinary echocardiography. Wiley-Blackwell, Chichester

Bove AA (2011) The cardiovascular system and diving risk. Undersea Hyperb Med 38:261-269

Cornell CC, Kittleson MD, Della Torre P, Häggström J and others (2004) Allometric scaling of M-mode cardiac measurements in normal adult dogs. J Vet Intern Med 18:311-321

Gray KN, Conklin RH (1974) Multiple birth and cardiac anomalies in the bottle-nosed dolphin. J Wildl Dis 10: 155-157

Hansson K, Häggström J, Kvart C, Lord P (2002) Left atrial to aortic root indices using two-dimensional and M-mode echocardiography in cavalier King Charles spaniels with and without left atrial enlargement. Vet Radiol Ultrasound 43:568-575

Johnson L (1999) Diagnosis of pulmonary hypertension. Clin Tech Small Anim Pract 14:231-236

Kastelein RA, Meijler FL (1989) Respiratory arrhythmia in the hearts of harbour porpoises. Aquat Mamm 15:57-63

Kittleson MD (1998) Septal defects. In: Kittleson MD, Kienle RD (eds) Small animal cardiovascular medicine. Mosby, St. Louis, MO, p 231-239

Ljungvall I, Höglund K, Carnabuci C, Tidholm A, Häggström J (2011) Assessment of global and regional left ventricular volume and shape by real-time 3-dimensional echocardiography in dogs with myxomatous mitral valve disease. J Vet Intern Med 25:1036-1043

Editorial responsibility: Michael Moore, Woods Hole, Massachusetts, USA
Penny DJ, Vick GW III (2011) Ventricular septal defect. Lancet 377:1103-1112

Powell JWB, Archibald RT, Cross CA, Rotstein DS, Soop VM, McFee WE (2009) Multiple congenital cardiac abnormalities in an Atlantic bottlenose dolphin (Tursiops truncatus). J Wildl Dis 45:839-842

Reed JZ, Chambers C, Hunter CJ, Lockyer C, Kastelein R, Fedak MA, Boutilier RG (2000) Gas exchange and heart rate in the harbour porpoise, Phocoena phocoena. J Comp Physiol B 170:1-10

Rishniw M, Erb HN (2000a) Prevalence and characterization of pulmonary regurgitation in normal adult dogs. J Vet Cardiol 2:17-21

Rishniw M, Erb HN (2000b) Evaluation of four 2-dimensional echocardiographic methods of assessing left atrial size in dogs. J Vet Intern Med 14:429-435

Scaglione FE, Bollo E, Pregel P, Chiappino L and others (2013) Heart pathologies in dolphins stranded along the northwestern Italian coast. Dis Aquat Org 107: $31-36$

Shakir L, Javeed A, Ashraf M, Riaz A (2011) Metronidazole and the immune system. Pharmazie 66:393-398

Sklansky M, Levine G, Havlis D, West N, Renner M, Rimmerman C, Stone R (2006) Echocardiographic evaluation of the bottlenose dolphin (Tursiops truncatus). J Zoo Wildl Med 37:454-463

Thomas WP, Gaber CE, Jacobs GJ, Kaplan PM, Lombard CW, Moise NS, Moses BL (1993) Recommendations for standards in transthoracic two-dimensional echocardiography in the dog and cat. J Vet Intern Med 7:247-252

Submitted: July 21, 2015; Accepted: January 29, 2016 Proofs received from author(s): March 11, 2016 